\title{
Mimar Sinan, Üsküdar Mihrimah Sultan Camii Akustiği Öncesi ve Sonrası
}

\author{
Ferhat Eröz
}

\section{Öz}

Mimar Sinan'ın camilerinin akustik verilerini belirlemek amacı ile 1987 yılında Kültür Bakanlığı destekli başlatılan araştırmada öncelikli olarak altı cami ele alınmıştır. Bu camilerde çınlama zamanı ölçümleri yapılmış ve olumlu sonuçlar elde edilmiştir. Bu çalışma 2013 yılında Üsküdar Mihrimah Sultan Camisinde tekrarlanmıştır. Bu sonuçların ışığında yapılan incelemelerde, akustik konforun aynı olamadığını ortaya koyan veriler elde edilmiştir. Diğer bir yandan, homojen ses dağılımı elde etmek ve ses enerjisi düşüşünü kontrol etmek amacı ile kullanılan akustik sistemlerin restorasyon esnasında değiştiği saptanmıştır. Bu çalışmada, 1987 yılı ile 2013 yılında yapılan ölçümler karşılaştırılmış ve irdelenmiştir.

Anahtar Kelimeler: Mimar Sinan, Restorasyon, Cami Akustiği, Akustik Resonator

\section{ARCHITECT SINAN, ÜSKÜDAR MIHRIMAH SULTAN MOSQUE ACOUSTICS BEFORE AND AFTER}

\begin{abstract}
The Project aimed to define the acoustical properties of the mosques designed by Architecture Sinan's has been started in 1987 of the Ministry of Culture supported. Üsküdar Mimhrimah Sultan mosque and five of them has been selected as pilot mosques and reverberation times of them were measured. This study was repeated in 2013 Üsküdar Mihrimah Sultan mosque. In the evaluation in the light of these results, the data revealed not the same acoustic comfort has been obtained. On the other hand, it was determined that change during the restoration of the acoustic system used to obtain a homogeneous sound propagation and control sound energy reduction on purpose. This study, were compared and examined of the measurements made 2013 and 1987.
\end{abstract}

Keywords: Architect Sinan, Restoration, Mosque Acoustic, Acoustic Resonator

Y. Iç Mimar ve Akustik Uzmanı Ferhat Eröz, Atılım Üniversitesi,

Güzel Sanatlar Tasarım ve Mimarlık Fakültesi, iç Mimarlık ve Çevre Tasarımı Bölümü, Ankara.

e-posta:erozferhat@yahoo.com 


\section{Giriş}

Kültür Bakanlığının isteği doğrultusunda Prof. Dr. Mutbul Kayılı tarafından Mimar Sinan camilerinin akustik performansını belirlemek amacı ile bir araştırma başlatılmıştır. Uzun bir süre gerektiren bu çalışmada öncelikli seçilen altı caminin çınlama zamanı ölçülerini kapsayan ilk bölüm 1987 yılında yapılmış (Şekil 1) olup, çalışmaların sonucunda Mimar Sinan döneminde akustik teknolojisinin gelişmiş olduğu elde edilmiş veriler doğrultusunda ortaya konulmuştur (Kayılı, 1988: 545). Elde edilen veriler, Mimar Sinan'ın hacim içinde duran dalgaların oluşturduğu olumsuzlukları ileri düzeyde bir bilgi ile akustik ve panel rezonatör kullanarak önlemesi dikkat çekicidir.

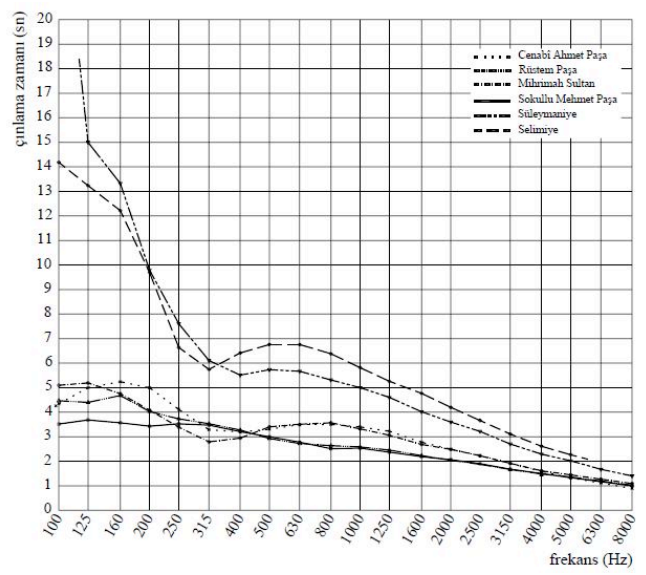

Şekil 1: 1987 Yılında Yapılan Ölçümde Camilerde Çınlama Zamanı (Kayılı, 1988: 171-175)

Akustik rezonatör uygulamasının daha öncelere kadar gitmesi cami akustiğinin önemini arttırmaktadır. Bu nedenle, makalemizde restorasyon esnasında değişime uğramış iç hacim, boşluklu rezonatör ve Mimar Sinan'ın konuya yaklaşımı ele alınacaktır. Daha önce yapılan çalışmalara değinelim.

\section{Yapılan Çalışmalar}

Başlangıçta altı cami öncelikle seçildiğinden 2013 yılında da seçilmiş altı cami dışında on beş adet caminin de ölçümleri gerçekleştirilmiştir. Bu camilerin içinde yer alan Üsküdar Mihrimah Sultan Camisi ölçümleri de tekrarlanmıştır. Bu camilerde hacim akustiğinin en önemli parametresi olan çınlama zamanı ölçülmüş elde edilen sonuçlar doğrultusunda araştırmalar yapılmış ve irdelenmiştir. Ölçümlerde kabul edilebilir arka plan gürültüsü 
$30 \mathrm{~dB}$ olarak belirlenmiştir. Burada ölçümlerin sağlıklı bir ortamda yapıldığı tespit edilmiştir (Beranek, 1954: 374).

Sonuç olarak elde edilen veriler, Mimar Sinan'ın akustik bilim ve teknolojisi bilgisinin olduğu ve konuyu bir kuram çerçevesinde ele alarak oluşabilecek problemlere daha önceden çözüm aradığı saptanmıştır.

\subsection{Akustik Ölçümü}

Üsküdar Mihrimah Sultan Cami akustik konfor özellikleri daha önce yapılan onarım ve restorasyon çalışmalarında bozulmuştur (Şekil 2, 3). En önemli sebeplerin başında, Mimar Sinan tarafından kullanılan, özellikle düşük ve orta frekanslarda sesin enerjisinin sönümlemesini sağlayan sıvanın yer yer raspalanarak yerine alçı veya çimento karışımlı harçlar kullanıldığı belirlenmiştir. Bununla beraber akustik rezonatör görevi yapan elemanların ağzının kapanması da diğer önemli bir etkendir. Mimar Sinan camilerinden Şehzade Camiinde duvarlarda rastlanan akustik rezonatörler, Edirnekapı Mihrimah Sultan Camiinde pandantiflerin üç köşesinde yer almakta ve Süleymaniye Camiinde kubbe kasnağında bulunduğu tespit edilmiştir (Eröz, 2013: 11-19).

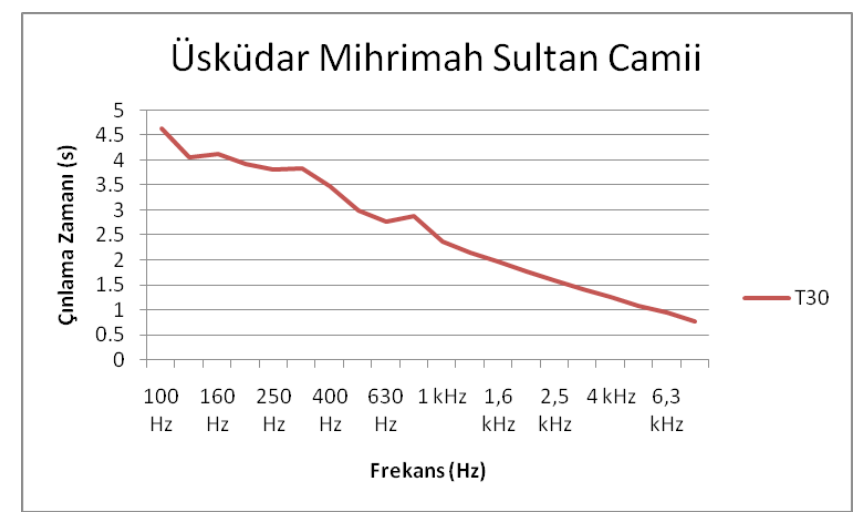

Şekil 2: 2013'deki Ölçümde Üsküdar Mihrimah Sultan Cami (1540-1548) (T30) Çınlama Zamanı (Eröz, 2013: 11-19)

Diğer bir yandan boş hacimlerde elde edilen ölçü sonuçlarını hesap yöntemi ile T60 verileri elde edilmiştir. Burada kullanıc faktörü eklenildiğinde bulunan çınlama zamanı eğrisi Mimar Sinan'ın bu konuya olan bilgisini olduğu ortaya çıkarmıştır (Şekil 4). 


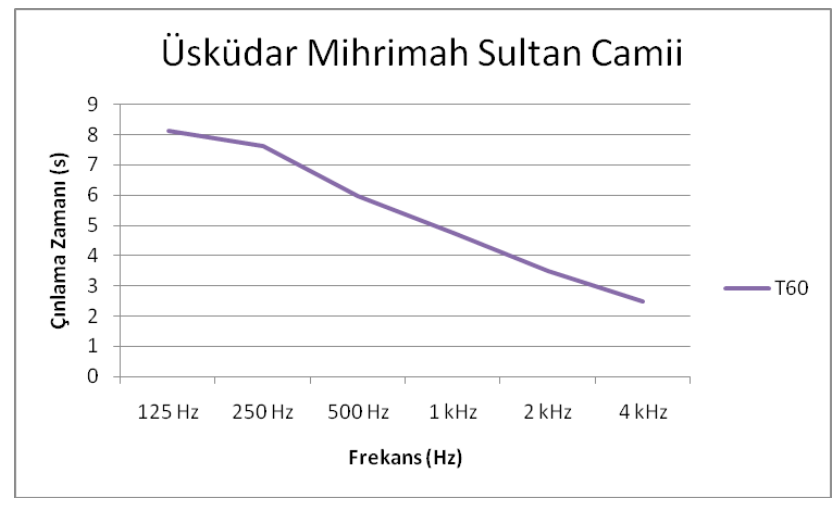

Şekil 3: 2013'deki Ölçümde Üsküdar Mihrimah Sultan Cami (Boş hacim T60 Hesap Yöntemi) Çınlama Zamanı (Eröz, 2013: hesaplamalar Eyring formülü kullanılarak yapılmıştır).

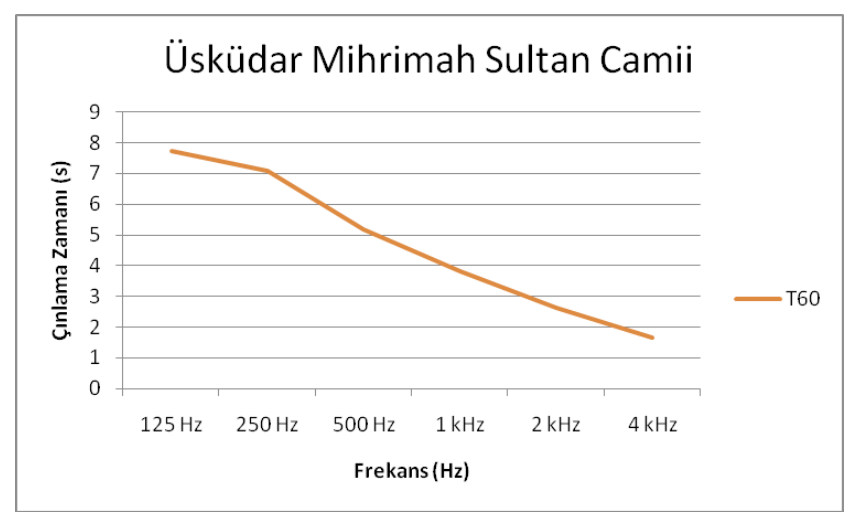

Şekil 4: 2013'deki Ölçümde Üsküdar Mihrimah Sultan Cami (Dolu hacim T60 Hesap Yöntemi) Çınlama Zamanı (Eröz, 2013: hesaplamalar Eyring formülü kullanılarak yapılmıştır).

\section{2. Çınlama Zamanı (RT) ve Erken Düşüş Zamanı (EDT) \\ Parametreleri}

Çınlama zamanı ve erken düşüş zamanı ölçümü ISO 354 ile beraber ISO 14130' da belirlenmiş standartlar sonucunda gerçekleştirilmiştir. Çınlama zamanı T30 (sesin enerjisinin $30 \mathrm{~dB}$ düşmesi için geçen süre) ve erken düşüş zamanı (sesin enerjisinin $10 \mathrm{~dB}$ düşmesi için geçen süre) olarak Brüel and Kjaer' in ses test cihazları kullanılarak ölçülmüştür.

Hacim akustiği tasarımında amaç "yeterli anlaşılabilme'nin" gerçekleştirilmesidir. Bunun için akustik tasarım temel olarak iki etapta ele alınır; ilk olarak "Homojen ses dağılımının sağlanması", ikinci olarak "Optimum çınlama zamanının gerçekleştirilmesi" dir (Sabine, 1932: 4766-145). 


\subsection{Homojen Ses Dağılımı}

Mimar Sinan'ın, hacim içinde homojen ses dağılımını elde etmek için geometrik form ve yapı elemanlarından yararlandığı tespit edilmiştir.

Bu amaçla; Hacimlerde paralel yüzeylerden kaçınmış ve bu yüzeylerde niş, taşıyıcı ayak (fil ayakları), mahfil, vb. unsurlar kullanarak bölümlemeler oluşturmuştur. Mukarnas, pandantif, taşıyıcı ayak vb. yapı elemanları ile sesin dağılmasını sağlamıştır. Kare plan şeması (kübik formun) akustik üzerindeki olumsuzluklarını, mihrap, niş, yarım kubbe, vb. yapı elemanları ile etkisiz hale gelmesini sağlamıştır.

\subsection{Ses Yutucu Elemanlar}

Çalışmalarımızda, homojen ses dağılımını sağladıktan sonra, optimum çınlama zamanını elde etmek için hacim içinde sesin enerjisi düşüşünü kontrol altına almak amacı ile yapı malzemelerini ve işleve bağlı unsurları (mahfil, mihrap, minber, kürsü, vb.) kullanarak gerçekleştirdiği görülmüştür. Bununla beraber özel sıvalar kullandığını, bu sıvaları özellikle keten ile birleştirerek gözenekli yüzeyler oluşturarak sesi yutuculuğunu arttırmış olduğu tespit edilmiştir. Diğer bir yandan, sesin yutuculuğu ile ilgili kullanıc faktörünün de, harim içi dolu olduğunda orta ve yüksek frekanslarda etkinliğinin bilindiği, bunun sonucu olarak hacim boş veya kullanıcının az olması dâhilinde ses yutma değerlerinin azalması ve çınlama zamanının uzamasının önlenmesine çalışıldığı belirlenmiştir. Bu amaçla döşemeye, yakın değerde ses yutma özelliğine sahip halı konulmuştur. Bu uygulama günümüzde halen kullanılmakta olup akustik teknolojisinin ana amaçlarından biridir.

\section{Akustik Rezonatörler}

Mimar Sinan'ın, hacim içinde ses enerjisi düşüşünü kontrol etmek amacı, yapılarında kullandığı malzeme ve yapı elemanları ile yapının kendisini kendisine karşı kullanmış olduğu belirlenmiştir. Burada, ilk bölümdeki araştırmada, Mimar Sinan'ın bu uygulamasının sonucunda elde ettiği başarı, çınlama zamanı ölçümlerinde elde edilen verilerle tespit edilmiştir. Ancak bu başarının, yapılan onarımlar ve restorasyon sonucunda olumsuz olarak etkilendiği Ferhat Eröz tarafından 2013 yılında yapılan ölçümlerle belirlenmiştir.

Mimar Sinan zamanında cami yapılarında sadece yansıtıcı, yutucu, dağıtıcı, vb., akustik önlemler dışında ileri düzey olarak akustik bilimi içinde yer alan akustik rezonatörlerden de yaralanıldığı görülmüştür. Bu yüzden akustik rezonatörlerin tanımlanması önemli bir konu olarak görülmüş ve tartışımasına gerek duyulmuştur. 


\subsection{Akustik Rezonatörlerin Tarihi}

Literatürde, boşluklu rezonatörlerle ilgili ilk bilgilerin Helmholtz ve Rayleigh tarafından verildiğini görüyoruz. İngiliz bilim adamı Rayleigh 1877 yılında yayınlanan "Theory of Acoustics" (Rayleigh, 1877: 5) adlı kitabında, bu tip rezonatörlerle ilgili ilk çalışmaların 1862 yılında Helmholtz tarafından yapıldığını belirterek boşluklu rezonatörlere "Helmholtz Rezonatörü" adını vermiştir. Daha sonraları çok sayıda araştırma yapılmasına rağmen, konunun tam anlamı ile ilk fiziksel tanımlaması 1953 yılında Ingard (Ingard, 1953: 1037) tarafından yapılmış ve araştırmacı arka arkaya yayınları ile bu tip sistemlere açıklık getirmiştir (Ingard, 1954: 151).

\subsection{Akustik Rezonatörlerin Fiziksel Tanımı}

Akustik bir sistemi oluşturan çeşitli elemanların boyutları, çoğunlukla sesin dalga boyundan küçüktür. Bu sistemlerin en önemli özelliklerinden biri de, genellikle boyutlarının küçüklüğüne rağmen alçak frekanslarda etkili olmalarıdır. Boyutlarının küçüklüğü nedeni ile sistemin içindeki akışkanın hareketi, toplu mekanik kütle-yay-zayıflatıcıdan oluşan mekanik bir sistemin benzeridir. Bu nedenle, boşluklu rezonatörler basit mekanik osilatörlerin veya LCR elektrik devrelerinin benzeri olarak incelenebilen (Şekil 5) akustik sistemlerdir (Kinsley, 1962: 192). Böyle bir sistem, V hacminde sınırları rijit bir boşluk, bu boşluğun dış ortam ile bağlantısını sağlayan $r$ yarıçapında ve I uzunluğunda bir boyundan oluşur (Kayılı, 2002: 7). 


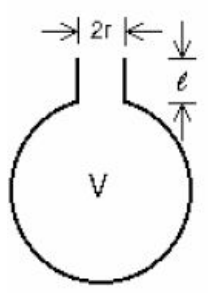

(a)

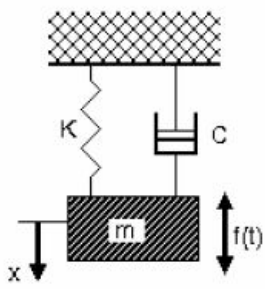

(b)

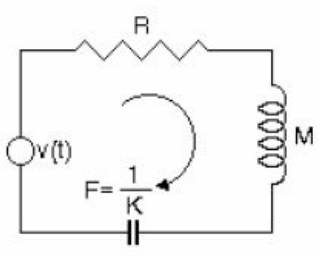

(c)

Şekil 5: a) Helmholtz rezonatörü, b) Eşdeğer mekanik sistem, c) Eşdeğer elektrik devresi

(Kinsley, 1962: 192).

Sistemin Kütlesi: Sistemin etkin kütlesi (m), boyundaki akışkan tarafından oluşturulur. Etkin durumda iken, sistemin boynundaki akışkan titreşim yapar. Bu titreşim sırasında, her iki uçta belirli miktarda akışkan, boyundaki akışkan ile beraber hareket eder. Bu nedenle, boynun iç tarafında $\delta 1$ ve dış tarafında $\delta n^{\prime}$ nin ilavesi ile 1 uzunluğundaki boyunda bulunan akışkan bunların toplamı $\sigma(\mathrm{m})$, kadar uzar (Ingard, 1953: 1037);

$$
\begin{aligned}
& \sigma=\delta 1+\delta n \\
& 1^{\prime}=1+\sigma
\end{aligned}
$$

Bu durumda, detaya girmeden kısaca belirtirsek, sistemde kütle görevi yapan ve kesit alanı S olan boyunda bulunan, 1' uzunluğunda ve $\rho$ yoğunluğunda akışkanın kütlesi,

$$
\mathrm{m}=\rho 1^{\prime} \mathrm{S}
$$

olur, burada; m: kütle

Sistemin Yay Kuvveti: Sistemin yay kuvvetini V hacmindeki boşlukta bulunan akışkanın hareketi oluşturur. Ses dalgaları nedeni ile sistemin boynundaki akışkanın (etkin kütlenin) titreşimi sonucu boşlukta bulunan akışkanda basınç dalgalanması oluşur. Bu basınç dalgalanması nedeni ile ortaya çıkan yay kuvveti, sistemin etkin sertlik sabiti K' yı oluşturur;

$$
K=\frac{\rho c^{2} S}{V}
$$

burada;
c: sesin havada yayılma hızı
$\rho$ : yoğunluk
K: sertlik sabiti
S: kesit alanı
V: hacim

(m/s)

$\left(\mathrm{kg} / \mathrm{m}^{3}\right)$

$(\mathrm{N} / \mathrm{m})$

$\left(\mathrm{m}^{2}\right)$

$\left(\mathrm{m}^{3}\right)$ 
Sistemin direnci: Sistemin direnci, boyundaki akışkan kütlesinin titreşim yaparak ses enerjisi yaymasında oluşan ışınlama direnci ve sürtünmeler nedeni ile boyunda oluşan iç direncin toplamından oluşur.

Boyunda titreşen akışkan kütlesi, serbest alanda titreşim yapan pistona benzetilirse, ışınlama direnci $\mathrm{Rr}$, şöyle yazılabilir;

$$
R_{r}=\frac{\rho c k^{2} S^{2}}{4 \pi}(\mathrm{Ns} / \mathrm{m})
$$

burada; $\quad$ k: açısal dalga sayısı $\quad(1 / m)$

Rt: ışınlama direnci ( $\quad$ s/m)

Işınlama direnci oranı $\mathrm{Or}=\mathrm{Rt} / \mathrm{\rho cS}$ olduğundan;

$$
\Theta_{r}=\left(\frac{k r}{2}\right)^{2} \quad \text { (birimsiz) }
$$

olur. Titreşim yapan akışkan kütlesinin sürtünmeler nedeni ile boyunda oluşturduğu iç direnç oranı $\Theta_{i}$ ise şöyle tanımlanmaktadır;

$$
\Theta_{i}=\frac{2}{\rho c}(\rho \mu \omega)^{\frac{1}{2}}\left(\varepsilon+0.5 \frac{1}{r}\right) \quad \text { (birimsiz) }
$$

burada;

$$
\begin{aligned}
& \omega: \text { açısal frekans (rad/s) } \\
& \varepsilon \text { : yutucu eleman ilavesi ile boyunda oluşan ilave } \\
& \text { direnç oranı (birimsiz) } \\
& \mu \text { : yapışkanlık } \\
& \left(1.86 \times 10^{-3} \mathrm{Ns} / \mathrm{m}^{2}\right)
\end{aligned}
$$

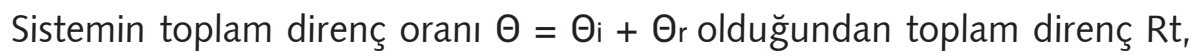
şöyle yazılır;

$$
R t=\rho c S\left(\Theta_{i}+\Theta_{r}\right)
$$

Serbest alanda sistemi etkileyen kuvvet SPe ${ }^{j \omega t}$, boyunda akışkanın hacimsel deplasmanı $X=\xi S$ ve hacimsel hız $(\partial x / \partial t)=(\partial 1 / \partial \mathrm{t}) \mathrm{S}$ olduğundan sistemin hareket denklemini şöyle yazabiliriz;

$$
M \frac{\partial^{2} X}{\partial t^{2}}+R_{A}=\frac{\partial X}{\partial t}+K_{A} X=P e^{j a t}
$$


burada;

$\xi:$ deplasman

$X$ : hacimsel deplasman $\left(\mathrm{m}^{3}\right)$

$P$ : basınç dalgası genliği

t: zaman (m)

$\left(\mathrm{N} / \mathrm{m}^{2}\right)$

(s)

Sonuç olarak, sistemi oluşturan bileşenler eşitlik (3.8)' den şöyle tanımlanabilir;

Akustik atalet:

Akustik direnç:

$$
M=\frac{\rho l^{\prime}}{S}
$$

1/Akustik Kapasitans: $\quad K_{A}=\frac{\rho c^{2}}{V} \quad(\mathrm{~N} / \mathrm{m} 5)$

Tekrar eşitlik (3.7)' a dönelim ve sistemin akustik empedansı $Z_{A}{ }^{\prime}$ yı yazalım;

$$
Z_{A}=R_{A}+i\left(\cos M-\frac{K_{A}}{\omega}\right)
$$

Akustik empedansın sanal kısmının O' a eşit olduğu frekansta mekanik rezonans oluşur. Buna göre mekanik rezonansın oluştuğu frekansı sanal kısım 0 olduğundan şöyle belirtebiliriz (3.12);

$$
\begin{aligned}
& \omega M-\frac{K_{A}}{\omega}=0 \quad \text { olduğundan, } \\
& \omega_{O}=\sqrt{\frac{K_{A}}{M}}=c \sqrt{\frac{S}{l^{\prime} V}} \quad(\mathrm{rad} / \mathrm{s})
\end{aligned}
$$

Bileşenleri yukarıda tanımlanan boşluklu rezonatörlerin ses enerjisini dağıtarak yansıtma ve yutma özelliklerini belirten Ingard, dağılarak yansıyan ve yutulan ses gücünü sırası ile şu eşitliklerle vermektedir;
$W s=S P^{2} \Theta r / 2 \rho c|\xi|^{2}$
$\mathrm{Wa}=\mathrm{SP} \mathrm{P}^{2} \mathrm{Oi} / 2 \rho \mathrm{gc}|\xi|^{2}$
(Watt)
(Watt)

Bunlara karşılık olan eşdeğer dağıtma kesit alanı os ve eşdeğer yutma kesit alanı $\sigma a$ ise şöyle tanımlanmaktadır; 


$$
\begin{aligned}
& \sigma_{s}=\frac{\Theta_{r}}{|\xi|^{2}} S \\
& \sigma_{a}=\frac{\Theta_{r}}{|\xi|^{2}} S
\end{aligned}
$$

burada;

$$
\xi \text { : toplam özgül akustik empedans oranı }
$$

(birimsiz)

$$
\begin{gathered}
\xi:(\Theta i+\Theta r)[1-\text { i } Q(\Omega-1 / \Omega)] \\
\Omega=\omega / \omega o \\
Q=\text { kalite faktörü }
\end{gathered}
$$

Eşitlik (3.15a) ve (3.15b) incelendiğinde oa ve os ' yi etkileyen ana faktörlerin $\Theta i$, Or ve Q eşitlik (3.15)' de छ' yı etkilemesi nedeni ile olduğu görülür.

Sistemin kalite faktörü Q;

$$
Q=\omega_{o} \frac{M}{R_{A}}=\frac{1}{\Theta} \sqrt{\frac{S I^{\prime}}{V}}=\frac{k_{o} I^{\prime}}{\Theta}
$$

eşitlikleri bulunur.

burada; $\quad$ ko: rezonans frekansta açısal dalga sayısı $(1 / m)$ olduğundan, Q' nun etkinliği yine $\Theta$ ' ya bağlı kalmaktadır.

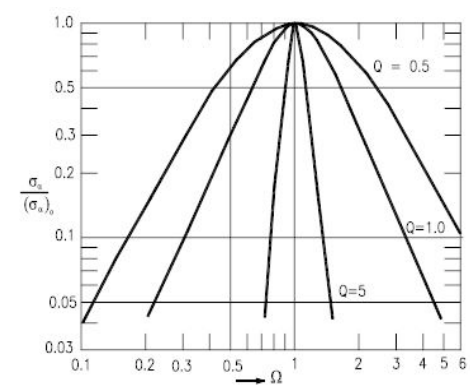

Şekil 6: $\sigma a$ ' nın $\Omega$ ve Q' ya bağlı olarak aldığı değerler (Eröz, 2012: 41).

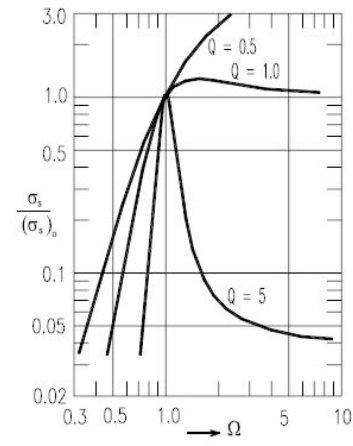

Şekil 7: os ' nın $\Omega$ ve $Q$ ' ya bağlı olarak aldığı değerler (Eröz, 2012: 42).

Eşitliklerde görüldüğü üzere $Q$ küçüldükçe gerek $\sigma a$ ve gerekse $\sigma s^{\prime}$ nin yeterli değer verdiği frekans bandı genişlemektedir. Şekil $\sigma^{\prime}$ da $\sigma a^{\prime}$ nın, 
rezonans frekansta elde edilen eşdeğer yutma kesit alanı ( $\sigma a))^{\prime}$ a oranı, $\Omega=\omega / \omega 0$ ' a Şekil 7' de os için verilmektedir. Fiziksel olarak rezonans prensibine göre yapılan uygulamalardır. Rezonans frekansta tam etki görülür.

\section{Mimar Sinan'ın Akustik Rezonatörleri}

Araştırmamızda, Üsküdar Mihrimah Sultan Camiinde rezonatör olması muhtemel bölgelere bakılmasına rağmen restorasyon sonrası kapatılması sonucunda, akustik rezonatörler bulunamamıştır. Bu camilerden biri olan Edirnekapı Mihrimah Sultan Camiinin restorasyon sonrası pandantiflerde bulunan ve ağızları açılan akustik rezonatörlerle beraber Süleymaniye, Şehzadebaşı camilerinde de ağızları açık halde bulunduğu tespit edilmiştir (Eröz, 2013: 11-19). Restorasyon çalışmaları esnasında bu tip rezonatörlerin ağızlarının sıvandığı belirlenmiştir (Barkan, 1972-1:72). Tespit edilmiş olan rezonatörler ise yüksekte olması dolayısıyla tam olarak incelenememiştir. Çalışmaların bir sonraki aşamasında akustik rezonatorler hakkında bilgi edinmekle beraber her birisinin frekans aralığının ölçülmesi gerekmektedir. Bu ölçümler akustik bilim açısından önemlidir.

Diğer önemli bir konu ise araştırmanın birinci bölümü olan ve Prof. Dr. Mutbul Kayılı tarafından hacim büyüklüğüne bağlı çınlama zamanı eğrileri içinde gösterilen camii eğrisidir ve 2013 yılında geliştirilmiş, sunulmuştur (Eröz, 2014: 6).

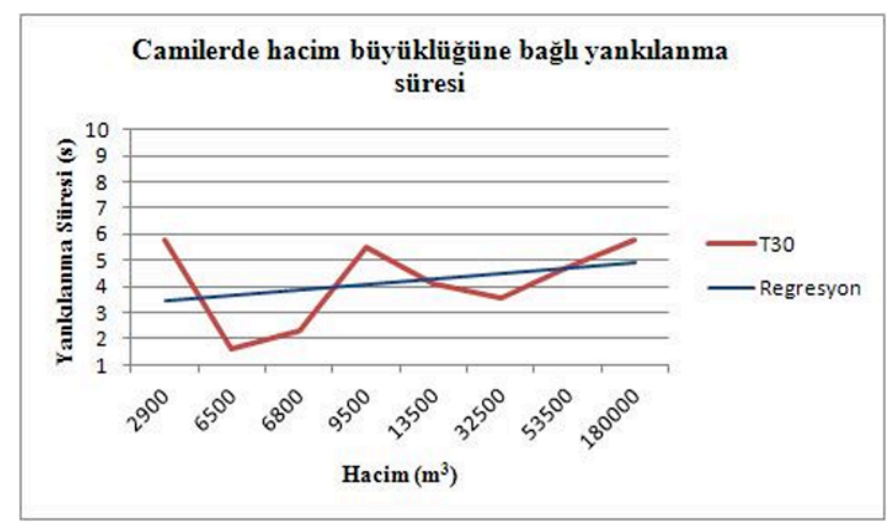

Şekil 8: Cami yapılarında hacim büyüklügüne bağlı çınlama süreleri (Eröz, 2014: 6) 


\section{Sonuç}

Bütün bu veriler ile Anadolu mimarisi, Osmanlı mimarisi ve Mimar Sinan döneminde akustik bilimin kullanıldığı, bu konudaki bilgi ve teknolojinin üst düzeyde olduğu tespit edilmiştir. Mimar Sinan'ın akustik amaçlı bir tasarım yaparak ortaya çıkacak sorunlara önceden akustik sistemlerle çözüm getirdiği anlaşılmıştır. Bir önceki bölümde verilmiş olan camii eğrisinin tam olarak belirlenmesi ve rezonatörlerin akustik konfor ve performans açısından önemli bir konu olduğu belirtilmiştir. Tarihi yapılarda restorasyon, kullanılacak malzeme seçimi, vb., konuların önemli olduğu saptanmıştır.

Sonuç olarak, dönemin akustik teknolojisinin ileri düzeyde olduğu ortaya konulmuştur. Restorasyon konusunun önemli olduğu tespit edilmiştir. $\mathrm{Bu}$ tür araştırmaların çoğaltılması, özellikle restorasyon esnasında bu konularda uzman olan disiplinlerinde projede yer alması gerekmektedir. 


\section{Kaynakça}

Beranek, L.,Leo. (1954). Acoustics, Acoustic Society of America through the American Institute of Physics. Inc.

Barkan, Ö.,L. (1972). Süleymaniye Cami ve İmareti İşaatı, Ankara, Türk Tarih Kurumu Basımevi.

Eröz, F. (2012). Maketlerin Akustik Ölçümlerde Kullanımı; Konser Salonu, Ölçekli Model ve Bilgisayar Modellemesinin Karşılaştırılması, Ankara, (Atılım Üniversitesi Yayımlanmamış Yüksek Lisans Tezi).

Eröz, F. (2013, 16-17 Aralık). Sinan ve Mimari Akustik, 10. Ulusal Akustik Kongresinde sunuldu, Istanbul.

Eröz, F. (2014, 15-19 Eylül). Mimar Sinan Yapılarında Geometrik Akustik, XVII. Uluslararası Türk Tarih Kongresinde sunuldu, Ankara.

Ingard, U. (1953). On The Theory and Design of Acoustics Resonators, J.A.S.A., vol. 25, issue 6, p. 1037.

Ingard, U. (1954). Perforated Facing and Sound Absorption, J.A.S.A., vol. 26, p. 151.

Kayılı, M. (1988). Mimar Sinan'ın Camilerindeki Akustik Verilerin Değerlendirilmesi, Mimarbaşı Koca Sinan'ın Yaşadığı Çağ ve Eserleri, Vakıflar Genel Müdürlüğü, İstanbul, 545-550.

Kayılı, M. (1988). Sinan's Acoustical Technology, Uluslararası Mimar Sinan Sempozyumu Bildirileri, Türk Tarih Kurumu Basımevi, Ankara, 171-175.

Kayılı, M. (2002). Evolution Of Acoustics And Effect Of Worship Buildings On It, PACS REFERENCE: 43.55.GX.

Kinsley, L. E., and Frey, A. R. (1962). Fundamentals of Acoustics, John Wiley and Sons Inc., New York.

Rayleigh, J. W. S. (1877). The Theory of Sound, Dover Publications, New York.

Sabine, P., E. (1932). Acoustic and Architecture, McGraw-Hill Book Company, Inc., New York. 